\title{
Implementasi Manajemen Risiko Sistem Kesehatan, Keselamatan Kerja dan Lingkungan (K3I) pada Pembangunan Flyover Pegangsaan 2 Kelapa Gading Jakarta Utara
}

\author{
Arif Rahman Hakim \\ Departemen Teknik Sipil, Fakultas Teknik, Universitas Mercu Buana, Jakarta \\ arifrahmanhakim11@gmail.com
}

Received: 17 Februari 2017 Revised: 19 September 2017 Accepted: 29 September 2017

\begin{abstract}
On construction of Flyover Pegangsaan 2 Kelapa Gading Jakarta Utara until March 2016 there are 4 accidents. Therefore, the health, safety and environment management system's applied to the implementation of construction works, thus minimizing the occurrence of occupational accidents and identify the risks from the highest to the lowest. Research methode is explaining variable and processing data at risk identification stage and risk analysis. The results obtained from the results of questionnaire given to 10 certified respondents and enrolled in A2K4 Indonesia and have experience at least 5 years in construction flyover. Assessment method using risk matrix sourced from AS/NZS 4360: 2004. The result of questionnaires is processed with risk index, the result's that workers fall from height in reinforcment, formwork and parapet work get the biggest result with scale 13,8 and at The lowest rank is risk workers exposed to respiratory disorders due to the compressor on roadsign works with scale 5.5. In the risk matrix analysis there are 3 jobs that are categorized as high risk include worker falls from height at reinforcement, formwork and parapet, full electric shock on electrical installation work, and materials falls from a height and hit the worker in erection work.
\end{abstract}

Keywords: Risk, health, safety and environment, flyover

\begin{abstract}
Abstrak
Pada pembangunan Flyover Pegangsaan 2 Kelapa Gading Jakarta Utara sampai dengan Maret 2016 terdapat 4 kecelakaan kerja. Untuk itu, sistem manajemen keselamatan, kesehatan kerja dan lingkungan diterapkan pada pelaksanaan pekerjaan konstruksi, sehingga menekan terjadinya kecelakaan kerja dan dapat mengidentifikasi risiko mulai yang paling tinggi sampai terendah. Metode Penelitian yang dilakukan yaitu menjelaskan variable dan mengolah data pada tahap identifikasi risiko dan analisis risiko. Hasil penelitian diperoleh dari hasil kuisioner yang diberikan kepada 10 responden yang bersertifikat dan terdaftar pada Asosiasi Ahli Keselamatan dan Kesehatan Kerja Konstruksi Indonesia dan memiliki pengalaman bekerja sedikitnya 5 tahun pada pembangunan flyover. Metode penilaian menggunakan matriks penilaian risiko yang bersumber dari AS/NZS 4360: 2004. Hasil pengisian kuesioner diolah melalui indeks risiko, hasilnya yaitu pekerja jatuh dari ketinggian pada pekerjaan pembesian, bekisting, dan parapet mendapat hasil paling besar yaitu dengan skala 13,8 dan pada peringkat terbawah yaitu risiko pekerja terkena gangguan pernapasan akibat compressor pada pekerjaan marka jalan yaitu dengan skala 5,5. Pada analisa risk matrix terdapat 3 pekerjaan yang tergolong high risk yaitu Pekerja jatuh dari ketinggian pada pekerjaan pembesian, bekisting, dan parapet, pekerja terkena sengatan listrik pada pekerjaan instalasi listrik, dan material terjatuh dari ketinggian dan menimpa pekerja saat erection.
\end{abstract}

Kata kunci: Risiko, kesehatan, keselamatan kerja dan lingkungan, flyover 


\section{Pendahuluan}

Salah satu hal yang menjadi perhatian dan sangat serius dalam pelaksanaan pekerjaan proyek adalah masalah kesehatan, keselamatan kerja dan lingkungan. Risiko tersebut merupakan dampak karena kompleksitas pekerjaan beserta kurangnya kontrol dari proyek sehingga nantinya akan berdampak negatif pada pembangunan proyek itu sendiri. Hal yang dilakukan untuk meminimalkan risiko yang akan timbul yaitu diperlukan adanya identifikasi, analisis, dan mitigasi terhadap kemungkinan risiko yang akan terjadi.

Masalah keselamatan dan kesehatan kerja (K3) secara umum di Indonesia masih sering terabaikan. Data Biro Pusat Statistik (BPS) memperlihatkan jumlah tenaga kerja di konstruksi jauh meningkat, dari 4.844.689 orang di tahun 2010 menjadi hampir dua kali lipat ditahun 2015, sebanyak 8.208.086 orang atau sekitar 7\% dari 114 juta orang pekerja (BPS, 2016). Sektor konstruksi juga dianggap salah satu sektor yang berisiko tinggi terhadap kecelakaan kerja. Data-data kecelakaan kerja yang dipaparkan sebelumnya tidak secara khusus memuat informasi kecelakaan kerja di konstruksi, namun beberapa sumber (Bpjs Ketenagakerjaan, 2016) (Pritanti, Purwoto, \& Solechan, 2012) mencatat paling tidak $30 \%$ kasus kecelakaan kerja terjadi di sektor konstruksi. Dengan jumlah porsi tenaga kerja yang besar dan juga risiko yang besar membuat kecelakaan kerja di sektor konstruksi merupakan aspek yang perlu diperhatikan.

Adapun pada Proyek Pembangunan Flyover Pegangsaan 2 Kelapa Gading Jakarta Utara sampai dengan Maret 2016 terdapat empat kecelakaan kerja. Hal ini seharusnya bisa diminimalisir dengan dilakukannya manajemen risiko.

Sistem manajemen keselamatan, kesehatan kerja dan lingkungan diharapkan dapat diterapkan pada pelaksanaan pekerjaan konstruksi, sehingga dapat menekan terjadinya kecelakaan kerja yang terjadi pada saat pelaksanaan pekerjaan konstruksi dan dapat mengidentifikasi risiko yang terjadi mulai dari yang paling tinggi sampai terendah.

Definisi risiko yang dikemukakan oleh Vaughan (1978) sebagai berikut: risk is the chance of loss (risiko adalah peluang terjadinya kerugian). Risiko juga dapat dihubungkan dengan kemungkinan terjadinya akibat negatif yang tak diinginkan atau tidak terduga, dengan kata lain kemungkinan itu akibat adanya ketidakpastian dimana ketidakpastian itu merupakan kondisi yang menyebabkan tumbuhnya risiko yang bersumber dari berbagai aktivitas.
Manajemen risiko merupakan aplikasi dari manajemen umum yang berhubungan dengan berbagai aktifitas yang dapat menimbulkan risiko. Siagian dan Sekarsari (2001) dalam pandangannya mendeskripsikan bahwa manajemen risiko juga harus mengelola keseluruhan risiko-risiko organisasi. Definisi tentang manajemen risiko memang sangat beragam, akan tetapi pada dasarnya manajemen risiko bersangkutan dengan cara yang digunakan oleh sebuah perusahaan untuk mencegah ataupun menanggulangi suatu risiko yang dihadapi (Kerzner, 2003).

Pengertian sistem manajemen K3 menurut standar OHSAS 18001:2007 adalah bagian dari sebuah sistem manajemen organisasi (perusahaan) yang digunakan untuk mengembangkan dan menerapkan kebijakan $\mathrm{K} 3$ dan mengelola risiko $\mathrm{K} 3$ organisasi (perusahaan) tersebut.

Elemen-elemen sistem manajemen keselamatan dan kesehatan kerja bisa beragam tergantung dari sumber dan aturan yang kita gunakan. Secara umum, standar sistem manajemen keselamatan kerja yang sering dijadikan rujukan ialah standar OHSAS 18001: 2007, ILO-OSH: 2001 dan Permenaker No.5 Tahun 1996 tentang sistem manajemen keselamatan dan kesehatan kerja.

Dalam menerapkan manajemen risiko $\mathrm{K} 3 \mathrm{~L}$ ada beberapa tahapan yang perlu dilakukan. Hal ini bertujuan agar proses manajemen risiko K3L dapat berjalan dengan tepat dan sesuai. Tahapan yang perlu dilakukan dalam menerapkan manajemen risiko K3L adalah menentukan konteks, melakukan identifikasi risiko, penilaian risiko, analisis risiko, mitigasi risiko.

Bagan proses manajemen risiko menurut AS/NZS 4360 : 2004 dapat dilihat pada Gambar 1.

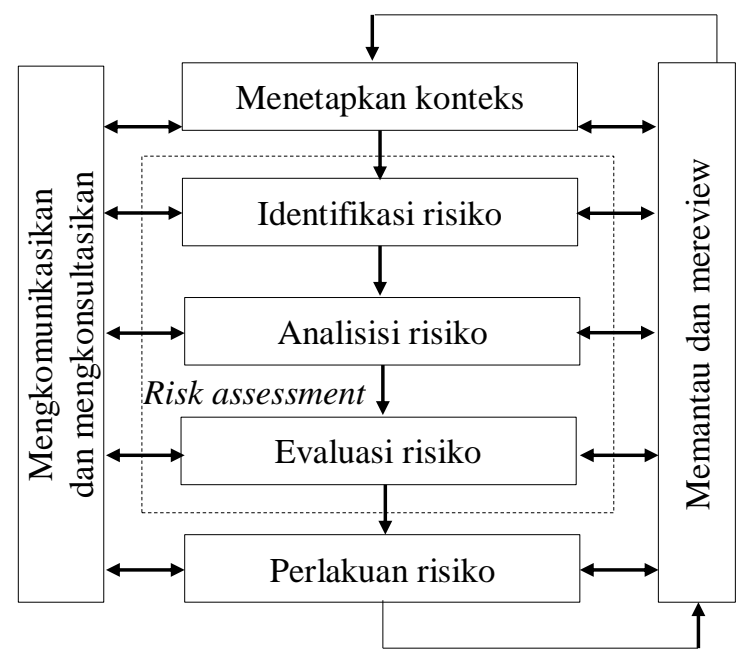

Gambar 1. Proses manajemen risiko AS/NZS 4360:2004 
Penentuan konteks akan menetapkan kriteria risiko yang akan diperoleh. Kriteria risiko didapat dari kombinasi kriteria tingkat kemungkinan dan keparahan. Dalam menentukan tingkat kemungkinan berpedoman AS/NZS 4360: 2004 dapat digambarkan pada Tabel 1.

Untuk menentukan nilai tingkat keparahan sehingga setiap kegiatan dapat dinilai tingkatan kemungkinannya berpedoman AS/NZS 4360: 2004 dapat digunakan Tabel 2. Untuk mengukur skala tingkatan risiko berpedoman AS/NZS 4360 : 2004 dapat digambarkan pada Tabel 3.

Tabel 1. Nilai tingkat kemungkinan

\begin{tabular}{|c|c|c|}
\hline $\begin{array}{l}\text { Likelihood/ } \\
\text { probability }\end{array}$ & Rating & Deskripsi \\
\hline Frequent & 5 & Selalu terjadi \\
\hline Probable & 4 & Sering terjadi \\
\hline Occasional & 3 & $\begin{array}{c}\text { Kadang-kadang dapat } \\
\text { terjadi }\end{array}$ \\
\hline Unlikely & 2 & Mungkin dapat terjadi \\
\hline Improbable & 1 & Sangat jarang terjadi \\
\hline
\end{tabular}

Tabel 2. Nilai tingkat keparahan

\begin{tabular}{|c|c|c|}
\hline Severity & Rating & Deskripsi \\
\hline Catastrophic & 5 & $\begin{array}{l}\text { Meninggal dunia, cacat } \\
\text { permanen / serius, } \\
\text { kerusakan lingkungan } \\
\text { yang parah, kebocoran } \\
\text { B3, kerugian finansial } \\
\text { yang sangat besar, biaya } \\
\text { pengobatan > 50 juta. }\end{array}$ \\
\hline Major & 4 & $\begin{array}{l}\text { Hilang hari kerja, cacat } \\
\text { permanen / sebagian, } \\
\text { kerusakan lingkungan } \\
\text { yang sedang, kerugian } \\
\text { finansial yang besar, biaya } \\
\text { pengobatan < } 50 \text { juta. }\end{array}$ \\
\hline $\begin{array}{c}\text { Moderatel } \\
\text { Serious }\end{array}$ & 3 & $\begin{array}{l}\text { Membutuhkan perawatan } \\
\text { medis, terganggunya } \\
\text { pekerjaan, kerugian } \\
\text { finansial cukup besar, } \\
\text { perlu bantuan pihak luar, } \\
\text { biaya pengobatan < } 10 \\
\text { juta. }\end{array}$ \\
\hline Minor & 2 & $\begin{array}{l}\text { Penanganan P3K, tidak } \\
\text { terlalu memerlukan } \\
\text { bantuan dari luar, biaya } \\
\text { finansial sedang, biaya } \\
\text { pengobatan }<1 \text { juta }\end{array}$ \\
\hline Negligible & 1 & $\begin{array}{l}\text { Tidak mengganggu proses } \\
\text { pekerjaan, tidak ada } \\
\text { cidera / luka, kerugian } \\
\text { financial kecil, biaya } \\
\text { pengobatan < } 100 \text { ribu. }\end{array}$ \\
\hline
\end{tabular}

Tabel 3. Skala tingkatan risiko

\begin{tabular}{cc}
\hline Risk rank & Deskripsi \\
\hline $17-25$ & Extreme high risk - risiko sangat tinggi \\
$10-16$ & High risk - risiko tinggi \\
$5-9$ & Medium risk - risiko sedang \\
$1-4$ & Low risk - risiko rendah \\
\hline
\end{tabular}

Selanjutnya melakukan penilaian dan analisis risiko untuk menentukan besarnya tingkatan risiko yang ada. Risiko diformulasikan sebagai fungsi dari kemungkinan terjadi (likelihood) dan dampak (impact). Atau indeks risiko = probabilitas (likelihood) $\times$ dampak (impact).

Analisis risiko dilakukan untuk menentukan besarnya suatu risiko dengan mempertimbangkan tingkat keparahan dan kemungkinan yang mungkin terjadi dengan membuat matriks risiko. Gambar matriks risiko berpedoman AS/NZS 4360: 2004 dapat digambarkan pada Gambar 2.

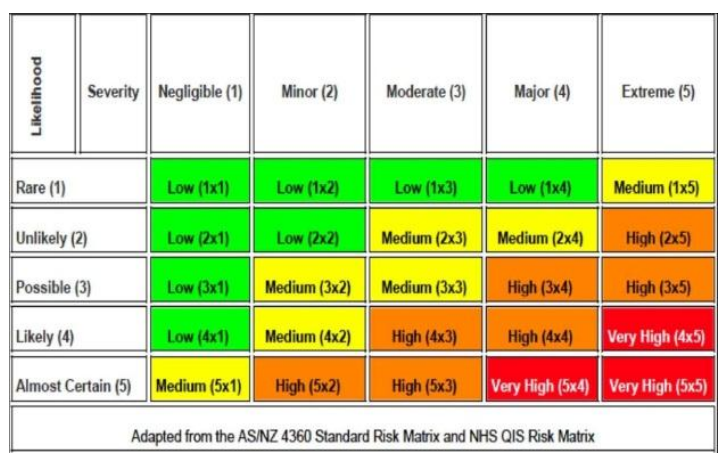

Gambar 2. Matriks risiko

\section{Mitigasi risiko}

Mitigasi risiko merupakan penanganan terhadap risiko yang dihadapi dan dapat dilakukan dengan beberapa pilihan (Flanagan \& Norman, 1993) yaitu menahan risiko (risk retention), mengurangi risiko (risk reduction), memindahkan risiko (risk transfer), menghindari risiko (risk avoidance) .

Pada penelitian terdahulu, ada beberapa penelitian terkait risiko yang terjadi pada proyek pembangunan, seperti hasil penelitian dari Wicaksono dan Singgih (2011) tentang Manajemen Risiko K3 pada Proyek Pembangunan Apartemen Puncak Permai Surabaya, diperoleh lima risiko tertinggi yaitu: (1) lifting material menggunakan tower crane terdapat risiko material terjatuh/sebagian besar dari material yang diangkat dengan total indeks risiko sebesar 13,95, (2) steel fixing, formwork installation, concreting, dan pekerjaan ekternal wall memiliki risiko terjatuh dari ketinggian dengan total indeks risiko sebesar 13,16, (3) installation electrical pipe, pasang pintu dan kusen kayu, eksternal wall, pasang keramik 
dan finishing (grinding, chipping, cutting) dengan total indeks risiko sebesar 12,76, (4) excavation terdapat risiko longsornya galian dengan total indeks risiko sebesar 12,47, (5) eksternal wall terdapat risiko gondola jatuh dengan total indeks risiko sebesar 11,88 .

Begitu pula penelitian sebelumnya dari Octavia (2012) tentang identifikasi dan analisa risiko konstruksi dengan metode failure mode and effect analysis (FMEA) dan fault tree analysis (FTA) pada Pembangunan Jalan Lingkar Nagreg V Bandung diperoleh hasil bahwa risiko-risiko yang relevan terjadi adalah kelongsoran, keterlambatan, retak, keruntuhan, material hilang lampu tidak nyala atau mati dan data tidak sesuai dokumen kontak. Risiko yang dominan terhadap proyek adalah kelongsoran pada pekerjaan timbunan tanah, terjadinya kelongsoran pada pekerjaan galian tanah, kelongsoran pada pekerjaan pengecoran lereng, terjadinya keruntuhan akibat pergeseran tanah pada pekerjaan bronjong dan keterlambatan pada proses pekerjaan timbunan tanah. Sedangkan tindak mitigasi yang dapat digunakan adalah selalu mengamati prakiraan cuaca, menggunakan staf berpengalaman, memberikan alat pengaman diri (APD) pada pekerja, dan memperpendek jarak quarry tanah.

Hasil penelitian yang didapat dari hasil penelitian sebelumnya oleh Soputan, Sompie, \& Mandagi (2014) tentang manajemen risiko K3 (Study kasus pada Pembangunan Gedung SMA Eben Haezar) didapat hasil nilai risiko yang tinggi, yaitu material terjatuh dari ketinggian dan menimpa pekerja dengan indeks risiko sebesar 20 dan penggolongan risiko pada very high risk. Untuk penggolongan risiko pada level high risk sebanyak 21 variabel yang dapat membahayakan pekerja dan pekerjaan, sedangkan untuk penggolongan pada level medium risk didapatkan sebanyak 18 variabel.

Penelitian-penelitian terdahulu banyak membahas terkait manajemen risiko $\mathrm{K} 3$ pada pembangunan konstruksi jenis gedung/apartemen, sehingga penulis meneliti terkait manajemen risiko $\mathrm{K} 3$ pada pembangunan konstruksi yang berbeda yaitu konstruksi flyover yang belum pernah diteliti sebelumnya. Hal tersebut diatas mendukung bahwa penelitian ini merupakan suatu kebaruan ilmiah, dan penulis menyatakan bahwa artikel ilmiah ini merupakan penelitian yang terbarukan.

Permasalahan penelitian ini yaitu terkait implementasi manajemen risiko sistem K3L pada pelaksanaan pembangunan flyover Pegangsaan 2Kelapa Gading - Jakarta Utara, yaitu identifikasi risiko dan menyusun peringkat risiko, serta langkah-langkah apa yang harus dilakukan (mitigasi risiko) sistem $\mathrm{K} 3 \mathrm{~L}$ agar meminimalkan dampak negatif yang mungkin terjadi pada pelaksanaan pembangunan flyover Pegangsaan 2 Kelapa Gading - Jakarta Utara.

Tujuan penelitian ini adalah untuk mengetahui identifikasi risiko, menyusun peringkat risiko, dan untuk mengetahui langkah-langkah yang dilakukan dalam meminimalisir risiko (mitigasi risiko) sistem K3L pada pelaksanaan pembangunan flyover Pegangsaan 2 - Kelapa Gading - Jakarta Utara.

\section{Metode Penelitian dan Bahan}

Metodologi penelitian ini dilakukan dengan menjelaskan variabel dan mengolah data pada tahap identifikasi risiko dan analisis risiko. Tujuan penelitian ini yaitu mendeskripsikan sejumlah variabel yang berkenaan dengan masalah dan unit yang diteliti antara permasalahan yang diuji, serta mengetahui identifikasi risiko, analisis, dan mitigasi risikonya. Kerangka metode penelitian dapat dilihat pada Gambar 3.

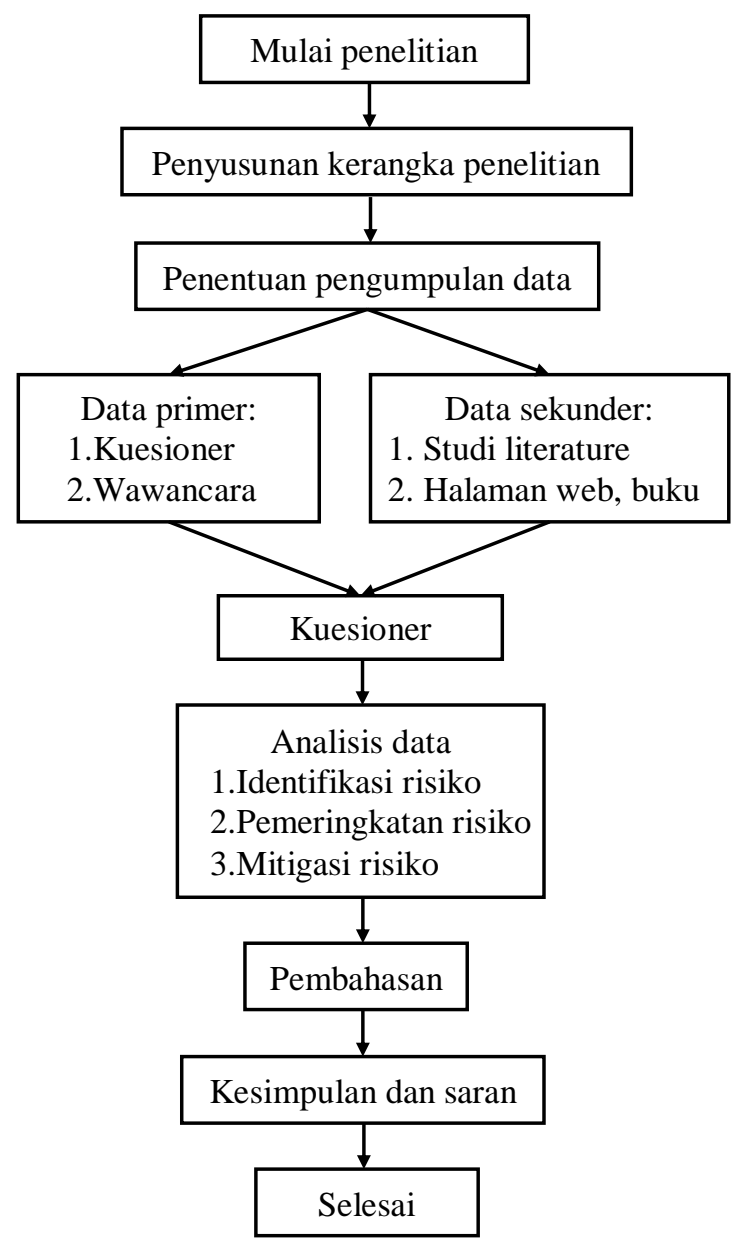

Gambar 3. Kerangka penelitian 


\section{Lokasi dan waktu penelitian}

Lokasi penelitian adalah proyek Pembangunan Flyover Pegangsaan 2 Kelapa Gading ini adalah dimulai dari Jalan Boulevard Timur (Sta.0+000) melintasi Jalan Pegangsaan 2, Kelapa Gading, Jakarta Utara dan berakhir di lokasi pengembangan perumahan (Sta. 0+969,107). Waktu penelitian dilaksanakan dari bulan Maret 2016 sampai pertengahan bulan Mei 2016.

\section{Pengumpulan data}

Referensi (Literature) dalam menyusun penelitian ini didapat dari buku-buku dan berbagai jurnal penelitian yang terkait dengan topik, maupun jurnal penelitian umum, serta referensi didapat dari berbagai website internet yang materinya terkait topik pembahasan yang relevan. Kegiatan pengumpulan data ini merupakan tahapan yang penting dilakukan agar penelitian ini dapat dilaksanakan. Pengumpulan data dibagi menjadi dua jenis, yaitu data primer dan data sekunder (data referensi).

Data primer didapat dari pengisian kuesioner dan wawancara kepada pakar tentang penilaian atau persepsi tentang manajemen risiko $\mathrm{K} 3 \mathrm{~L}$ pada pekerjaan pembangunan flyover. Instrumen yang digunakan adalah kuesioner yang berbentuk checklist. Langkah-langkah penyusunan instrument dimulai dengan penjabaran menjadi variabel, indikator dan komponen-komponennya. Seluruh pertanyaan yang disusun ditempatkan dalam lembaran instrumen kuesioner. Data sekunder diperoleh dari pihak manajemen proyek, selain itu didapat juga dari literature seperti halaman internet, buku, media elektronik dan sumbersumber yang menunjang dalam penelitian ini.

\section{Subjek penelitian}

Subjek penelitian atau sampel sebanyak 30 orang dengan level pekerja konsruksi di kontraktor dengan memberikan kuisioner yang nantinya akan diolah menjadi data dengan data umum responden seperti pada Tabel 4.

\section{Analisa Data dan Pembahasan}

Pada proses awal yaitu identifikasi risiko ini merupakan tahap pertama untuk menentukan variabel risiko yang akan diteliti dan menetapkan kerangka kerja untuk implementasi secara keseluruhan, menyusun dan melakukan kedalam kategori risiko. Hal ini menjelaskan bahwa risiko diidentifikasi sejak dini, walaupun yang ditimbulkan kecil namun perlu diantisipasi untuk pengelolaan risiko.

Tabel 4 Variabel Risiko pada pembangunan Flyover

\begin{tabular}{|c|c|c|}
\hline $\begin{array}{c}\text { Umur } \\
\text { responden }\end{array}$ & $\begin{array}{c}\text { Pengalaman } \\
\text { kerja }\end{array}$ & $\begin{array}{c}\text { Pendidikan } \\
\text { terakhir }\end{array}$ \\
\hline $\begin{array}{l}<25 \text { tahun }=4 \\
\text { orang }\end{array}$ & $\begin{array}{l}5 \text { tahun }=15 \\
\text { orang }\end{array}$ & $\mathrm{S} 2=1$ orang \\
\hline $\begin{array}{l}26-30 \text { tahun }=14 \\
\text { orang }\end{array}$ & $\begin{array}{l}6-10 \text { tahun }= \\
10 \text { orang }\end{array}$ & $\mathrm{S} 1=20$ orang \\
\hline $\begin{array}{l}31-35 \text { tahun }=8 \\
\text { orang }\end{array}$ & $\begin{array}{l}11-15 \text { tahun } \\
=4 \text { orang }\end{array}$ & D3 $=6$ orang \\
\hline $\begin{array}{l}\text { Umur }>36 \text { tahun } \\
=4 \text { orang }\end{array}$ & $\begin{array}{l}15-20 \text { tahun } \\
=1 \text { orang }\end{array}$ & $\begin{array}{l}\text { SLTA }=3 \\
\text { orang }\end{array}$ \\
\hline $\begin{array}{l}\text { Total }=30 \\
\text { orang }\end{array}$ & $\begin{array}{l}\text { Total }=30 \\
\text { orang }\end{array}$ & $\begin{array}{l}\text { Total }=30 \\
\text { orang }\end{array}$ \\
\hline
\end{tabular}

Variabel yang didapat bersumber dari literature dan telah divalidasi oleh Asosiasi Ahli Keselamatan dan Kesehatan Kerja Konstruksi (A2K4) - Indonesia. Variabel tersebut kemudian disusun lalu dilakukan kuesioner kepada 10 responden yang bersertifikat dan terdaftar pada Asosiasi Ahli Keselamatan dan Kesehatan Kerja Konstruksi Indonesia dan memiliki pengalaman bekerja sedikitnya lima tahun pada pembangunan flyover, sehingga nantinya akan didapatkan pemeringkatan risiko setelah hasil dari kuesionr tersebut dianalisis.

Hasil yang didapat yaitu jenis kegiatan dan variabel yang ada pada kegiatan tersebut. Pada masing-masing pekerjaan tersebut yang merupakan bagian dari peristiwa risiko (risk event) yang meliputi kegiatan pekerjaan (segment) dengan variabel risiko yang mungkin terjadi pada pekerjaan tersebut telah dilakukan pemetaan. Variabel risiko pada pembangunan flyover dapat dilihat pada Tabel 5.

\section{Penilaian Risiko}

Penilaian risiko adalah penilaian yang didapatkan dari data primer melalui hasil kuisioner telah diisi para responden. Bentuk dari kuesioner itu sendiri merupakan checklist seperti Tabel 6. Penilaian resiko di peroleh melalui peluang (probability) $\mathrm{x}$ dampak (impact).

Risiko yang perlu diperhatikan adalah risiko yang memiliki probabilitas yang sangat besar untuk terjadinya suatu kecelakaan kerja. Hal tersebut nantinya harus mendapatkan perhatian, sehingga risiko tersebut dapat dimitigasi dengan baik. Hasil hitungan indeks risiko dapat dilihat pada Tabel 7 . 
Tabel 5. Variabel risiko pada pembangunan flyover

\begin{tabular}{|c|c|c|}
\hline \multirow{2}{*}{ No } & \multicolumn{2}{|r|}{ Peristiwa Risiko (Risk Event) } \\
\hline & Kegiatan & Variabel \\
\hline \multirow[t]{3}{*}{1.} & Galian tanah dengan Excavator & Peralatan excavation menabrak fasilitas/pekerja yang ada di sekitarnya \\
\hline & & Tanah longsor/runtuhnya dinding samping \\
\hline & & Pekerja/kendaraan terjatuh ke lubang galian \\
\hline & $\begin{array}{l}\text { Lifting Material dengan service } \\
\text { crane }\end{array}$ & pekerja/fasilitas tertimpa material \\
\hline 3. & Pemotongan Tiang Bore Pile & Pekerja terluka oleh alat \\
\hline \multirow[t]{2}{*}{4.} & Erection & Alat melukai pekerja/ merusak fasilitas \\
\hline & & Material terjatuh dari ketinggian dan menimpa pekerja \\
\hline \multirow[t]{3}{*}{5.} & Pembesian, Bekisting, dan Parapet & Pekerja jatuh dari ketinggian \\
\hline & & Bekisting jatuh dan menimpa pekerja/fasilitas \\
\hline & & Pekerja terluka ketika bekerja \\
\hline & Pengecoran & Pekerja jatuh dari ketinggian \\
\hline & & Pekerja terjatuh saat mendirikan cetakan beton \\
\hline & Perkerasan Jalan & Pekerja terkena semprotan perekat (aspal cair) \\
\hline & & Gangguan pernafasan akibat debu \\
\hline & Pekerjaan Marka Jalan & Pekerja terkena gangguan pernapasan akibat compressor \\
\hline & Instalasi Kabel & Terluka ketika bekerja oleh alat tang press hydrolic \\
\hline \multirow{2}{*}{\multicolumn{2}{|c|}{ 10. Instalasi listrik }} & Terdapat percikan api dan menimbulkan kebakaran \\
\hline & & Pekerja terkena sengatan listrik \\
\hline
\end{tabular}

Tabel 6. Kuisioner penilaian risiko

\begin{tabular}{|c|c|c|c|c|c|c|c|}
\hline \multirow{3}{*}{ No } & \multicolumn{2}{|c|}{ Peristiwa risiko (risk event) } & \multicolumn{5}{|c|}{ Penilaian } \\
\hline & & & 1 & 2 & 3 & 4 & 5 \\
\hline & Kegiatan & Variabel & $\begin{array}{c}\text { Sangat tdk } \\
\text { relevan }\end{array}$ & $\begin{array}{c}\text { Tidak } \\
\text { relevan }\end{array}$ & $\begin{array}{l}\text { Cukup } \\
\text { relevan }\end{array}$ & Relevan & $\begin{array}{l}\text { Sangat } \\
\text { relevan }\end{array}$ \\
\hline \multirow[t]{2}{*}{1} & $\begin{array}{l}\text { Galian tanah } \\
\text { dengan excavator }\end{array}$ & $\begin{array}{l}\text { Peralatan excavation menabrak } \\
\text { fasilitas/pekerja yang ada di } \\
\text { sekitarnya. }\end{array}$ & - & - & - & - & - \\
\hline & & $\begin{array}{l}\text { Pekerja/kendaraan terjatuh ke } \\
\text { lubang galian. }\end{array}$ & - & - & - & - & - \\
\hline 2 & $\begin{array}{l}\text { Lifting material } \\
\text { dengan service } \\
\text { crane }\end{array}$ & $\begin{array}{l}\text { pekerja/fasilitas tertimpa } \\
\text { material. }\end{array}$ & - & - & - & - & - \\
\hline & & $\begin{array}{l}\text { Material terjatuh dari ketinggian } \\
\text { dan menimpa pekerja. }\end{array}$ & - & - & - & - & - \\
\hline \multirow[t]{3}{*}{5} & Pembesian, & Pekerja jatuh dari ketinggian. & - & - & - & - & - \\
\hline & $\begin{array}{l}\text { bekisting, dan } \\
\text { parapet }\end{array}$ & $\begin{array}{l}\text { Bekisting jatuh dan menimpa } \\
\text { pekerja/fasilitas. }\end{array}$ & - & - & - & - & - \\
\hline & & Pekerja terluka ketika bekerja. & - & - & - & - & - \\
\hline \multirow[t]{2}{*}{6} & Pengecoran & Pekerja jatuh dari ketinggian. & - & - & - & - & - \\
\hline & & $\begin{array}{l}\text { Pekerja terjatuh saat mendirikan } \\
\text { cetakan beton. }\end{array}$ & - & - & - & - & - \\
\hline \multirow[t]{2}{*}{10} & Instalasi listrik & $\begin{array}{l}\text { Terdapat percikan api dan } \\
\text { menimbulkan kebakaran. }\end{array}$ & - & - & - & - & - \\
\hline & & Pekerja terkena sengatan listrik . & - & - & - & - & - \\
\hline
\end{tabular}


Tabel 7. Hasil Indeks Risiko

\begin{tabular}{|c|c|c|c|c|c|}
\hline No & Kegiatan & Variabel & $\begin{array}{c}\text { Rata-rata } \\
\text { peluang }\end{array}$ & $\begin{array}{c}\text { Rata-rata } \\
\text { dampak }\end{array}$ & $\begin{array}{c}\text { Risiko }= \\
\text { (peluang } \mathrm{x} \text { dampak) }\end{array}$ \\
\hline \multirow[t]{3}{*}{1.} & $\begin{array}{l}\text { Galian tanah } \\
\text { dengan excavator }\end{array}$ & $\begin{array}{l}\text { Peralatan excavation } \\
\text { menabrak fasilitas/pekerja } \\
\text { yang ada di sekitarnya. }\end{array}$ & 2,1 & 2,9 & 6,09 \\
\hline & & $\begin{array}{l}\text { Tanah longsor/ runtuhnya } \\
\text { dinding samping. }\end{array}$ & 2,3 & 3,1 & 7,13 \\
\hline & & $\begin{array}{l}\text { Pekerja/kendaraan terjatuh } \\
\text { ke lubang galian. }\end{array}$ & 2,2 & 3,1 & 6,82 \\
\hline 2. & $\begin{array}{l}\text { Lifting material } \\
\text { dengan service } \\
\text { crane }\end{array}$ & $\begin{array}{l}\text { pekerja/fasilitas tertimpa } \\
\text { material. }\end{array}$ & 2,3 & 3,9 & 8,97 \\
\hline 3. & $\begin{array}{l}\text { Pemotongan tiang } \\
\text { bore pile }\end{array}$ & Pekerja terluka oleh alat. & 2,4 & 3,1 & 7,44 \\
\hline \multirow[t]{2}{*}{4.} & Erection & $\begin{array}{l}\text { Alat melukai pekerja/ } \\
\text { merusak fasilitas. } \\
\text { Material terjatuh dari }\end{array}$ & 2,3 & 3,2 & 7,36 \\
\hline & & $\begin{array}{l}\text { ketinggian dan menimpa } \\
\text { pekerja. }\end{array}$ & 2,5 & 4,2 & 10,50 \\
\hline \multirow[t]{3}{*}{5.} & $\begin{array}{l}\text { Pembesian, } \\
\text { bekisting, dan }\end{array}$ & $\begin{array}{l}\text { Pekerja jatuh dari } \\
\text { ketinggian. }\end{array}$ & 3,0 & 4,6 & 13,80 \\
\hline & parapet & $\begin{array}{l}\text { Bekisting jatuh dan } \\
\text { menimpa pekerja/fasilitas. }\end{array}$ & 2,6 & 3,8 & 9,88 \\
\hline & & $\begin{array}{l}\text { Pekerja terluka ketika } \\
\text { bekerja. }\end{array}$ & 2,7 & 2,4 & 6,48 \\
\hline \multirow[t]{2}{*}{6.} & Pengecoran & $\begin{array}{l}\text { Pekerja jatuh dari } \\
\text { ketinggian. }\end{array}$ & 2,1 & 4,1 & 8,61 \\
\hline & & $\begin{array}{l}\text { Pekerja terjatuh saat } \\
\text { mendirikan cetakan beton. }\end{array}$ & 2,0 & 3,4 & 6,80 \\
\hline \multirow[t]{2}{*}{7.} & Perkerasan jalan & $\begin{array}{l}\text { Pekerja terkena semprotan } \\
\text { perekat (aspal cair). }\end{array}$ & 2,5 & 2,6 & 6,50 \\
\hline & & $\begin{array}{l}\text { Gangguan pernafasan } \\
\text { akibat debu. }\end{array}$ & 2,9 & 2,5 & 7,25 \\
\hline 8. & $\begin{array}{l}\text { Pekerjaan marka } \\
\text { jalan }\end{array}$ & $\begin{array}{l}\text { Pekerja terkena gangguan } \\
\text { pernapasan akibat } \\
\text { compressor. }\end{array}$ & 2,5 & 2,2 & 5,50 \\
\hline 9. & Instalasi kabel & $\begin{array}{l}\text { Terluka ketika bekerja } \\
\text { oleh alat tang press } \\
\text { hydrolic. }\end{array}$ & 2,1 & 2,9 & 6,09 \\
\hline \multirow[t]{2}{*}{10.} & Instalasi listrik & $\begin{array}{l}\text { Terdapat percikan api dan } \\
\text { menimbulkan kebakaran }\end{array}$ & 2,1 & 3,5 & 7,35 \\
\hline & & $\begin{array}{l}\text { Pekerja terkena sengatan } \\
\text { listrik. }\end{array}$ & 2,8 & 4,1 & 11,48 \\
\hline
\end{tabular}

\section{Analisis Level, Matriks, Dan Mitigasi Risiko}

Pengertian dari analisis level risiko yaitu analisis yang meliputi faktor penilaian, karakterisasi, komunikasi, manajemen dan kebijakan yang berkaitan dengan risiko tersebut. Dari hasil pengolahan data tersebut dan telah dilakukan analisis level risiko, shingga dapat diurutkan hasil indeks resiko dari yang paling tertinggi sampai yang terkecil atau biasa disebut pemeringkatan risiko. Sehingga dapat diketahui urutan mulai dari peringkat yang paling tertinggi sampai kepada yang terendah. Risiko tersebut dikelompokan dengan risiko yang very high, high, medium, dan low.

Dan dengan menggunakan matriks risiko, hasil dari indeks risiko terhadap variabel risiko dapat dipetakan. Hasil dari penggolongan matriks, peringkat matriks, dan mitigasi risiko terhadap variabel dan penanganannya dapat dilihat pada Tabel 8 . 
Tabel 8. Peringkat, matriks, dan mitigasi risiko

\begin{tabular}{|c|c|c|c|c|c|c|}
\hline No. & Kegiatan & Variabel & $\begin{array}{l}\text { Risiko = } \\
\text { (peluang x } \\
\text { dampak) }\end{array}$ & $\begin{array}{c}\text { Golongan } \\
\text { matriks } \\
\text { risiko }\end{array}$ & $\begin{array}{c}\text { Mitigasi } \\
\text { risiko }\end{array}$ & Penanganan \\
\hline 1 & $\begin{array}{l}\text { Pembesian, } \\
\text { bekisting, } \\
\text { dan parapet }\end{array}$ & $\begin{array}{l}\text { Pekerja } \\
\text { jatuh dari } \\
\text { ketinggian }\end{array}$ & 13,80 & High & $\begin{array}{l}\text { Risk } \\
\text { reduction }\end{array}$ & $\begin{array}{l}\text { Menerapkan aturan yang jelas sesuai } \\
\text { dengan metode pelaksanaan } \\
\text { pekerjaan berdasarkan sistem } \\
\text { manajemen keselamatan dan } \\
\text { kesehatan kerja khususnya mengenai } \\
\text { standar alat pelindung diri (APD) } \\
\text { bahwa pihak kontraktor wajib } \\
\text { menyediakan peralatan keselamatan } \\
\text { standar. } \\
\text { Mengasuransikan semua pekerja dan } \\
\text { pelaksana yang terlibat dalam proyek } \\
\text { melalui Jaminan Sosial Tenaga Kerja } \\
\text { (Jamsostek). }\end{array}$ \\
\hline 2 & $\begin{array}{l}\text { Instalasi } \\
\text { listrik }\end{array}$ & $\begin{array}{l}\text { Pekerja } \\
\text { terkena } \\
\text { sengatan } \\
\text { listrik }\end{array}$ & 11,48 & High & $\begin{array}{l}\text { Risk } \\
\text { reduction }\end{array}$ & $\begin{array}{l}\text { Menerapkan aturan yang jelas sesuai } \\
\text { dengan metode pelaksanaan } \\
\text { pekerjaan berdasarkan sistem } \\
\text { manajemen keselamatan dan } \\
\text { kesehatan kerja (SMK3) khususnya } \\
\text { mengenai standar APD. } \\
\text { Mengasuransikan semua pekerja dan } \\
\text { pelaksana yang terlibat dalam proyek } \\
\text { melalui Jamsostek. }\end{array}$ \\
\hline 3 & Erection & $\begin{array}{l}\text { Material } \\
\text { terjatuh dari } \\
\text { ketinggian } \\
\text { dan } \\
\text { menimpa } \\
\text { pekerja }\end{array}$ & 10,50 & High & $\begin{array}{l}\text { Risk } \\
\text { reduction }\end{array}$ & $\begin{array}{l}\text { Penggunaan standar APD. Dan } \\
\text { menerapkan aturan yang jelas sesuai } \\
\text { dengan metode pelaksanaan } \\
\text { pekerjaan berdasarkan SMK3. }\end{array}$ \\
\hline 4 & $\begin{array}{l}\text { Pembesian, } \\
\text { bekisting, } \\
\text { dan parapet }\end{array}$ & $\begin{array}{l}\text { Bekisting } \\
\text { jatuh dan } \\
\text { menimpa } \\
\text { pekerja/fasi } \\
\text { litas }\end{array}$ & 9,88 & Medium & $\begin{array}{l}\text { Risk } \\
\text { reduction }\end{array}$ & $\begin{array}{l}\text { Penggunaan standar APD dan } \\
\text { penerapan aturan sesuai dengan } \\
\text { metode pelaksanaan pekerjaan } \\
\text { berdasarkan SMK3. }\end{array}$ \\
\hline 5 & $\begin{array}{l}\text { Lifting } \\
\text { material } \\
\text { dengan } \\
\text { service } \\
\text { crane }\end{array}$ & $\begin{array}{l}\text { pekerja/fasi } \\
\text { litas } \\
\text { tertimpa } \\
\text { material }\end{array}$ & 8,97 & Medium & $\begin{array}{l}\text { Risk } \\
\text { reduction }\end{array}$ & $\begin{array}{l}\text { Penggunaan standar APD dan } \\
\text { penerapan aturan sesuai dengan } \\
\text { metode pelaksanaan pekerjaan } \\
\text { berdasarkan SMK3. }\end{array}$ \\
\hline 6 & Pengecoran & $\begin{array}{l}\text { Pekerja } \\
\text { jatuh dari } \\
\text { ketinggian }\end{array}$ & 8,61 & Medium & $\begin{array}{l}\text { Risk } \\
\text { reduction }\end{array}$ & $\begin{array}{l}\text { Menerapkan aturan yang jelas sesuai } \\
\text { dengan metode pelaksanaan } \\
\text { pekerjaan berdasarkan SMK3 } \\
\text { khususnya mengenai standar APD. } \\
\text { Mengasuransikan semua pekerja dan } \\
\text { pelaksana yang terlibat dalam proyek } \\
\text { melalui Jamsostek. }\end{array}$ \\
\hline 7 & $\begin{array}{l}\text { Pemotongan } \\
\text { Tiang bore } \\
\text { pile }\end{array}$ & $\begin{array}{l}\text { Pekerja } \\
\text { terluka oleh } \\
\text { alat }\end{array}$ & 7,44 & Medium & $\begin{array}{l}\text { Risk } \\
\text { reduction }\end{array}$ & $\begin{array}{l}\text { Penggunaan standar APD dan } \\
\text { penerapan aturan sesuai dengan } \\
\text { metode pelaksanaan pekerjaan } \\
\text { berdasarkan SMK3. }\end{array}$ \\
\hline 8 & Erection & $\begin{array}{l}\text { Alat } \\
\text { melukai } \\
\text { pekerja/ } \\
\text { merusak } \\
\text { fasilitas }\end{array}$ & 7,36 & Medium & $\begin{array}{l}\text { Risk } \\
\text { reduction }\end{array}$ & $\begin{array}{l}\text { Penggunaan standar APD dan } \\
\text { penerapan aturan sesuai dengan } \\
\text { metode pelaksanaan pekerjaan } \\
\text { berdasarkan SMK3. }\end{array}$ \\
\hline
\end{tabular}


Tabel 9. Peringkat, matriks, dan mitigasi risiko (lanjutan)

\begin{tabular}{|c|c|c|c|c|c|c|}
\hline No. & Kegiatan & Variabel & $\begin{array}{c}\text { Risiko }= \\
\text { (peluang } \mathbf{x} \\
\text { dampak) }\end{array}$ & $\begin{array}{c}\text { Golongan } \\
\text { matriks } \\
\text { risiko }\end{array}$ & $\begin{array}{l}\text { Mitigasi } \\
\text { risiko }\end{array}$ & Penanganan \\
\hline 9 & $\begin{array}{l}\text { Instalasi } \\
\text { listrik }\end{array}$ & $\begin{array}{l}\text { Terdapat } \\
\text { percikan api } \\
\text { dan } \\
\text { menimbulkan } \\
\text { kebakaran }\end{array}$ & 7,35 & Medium & $\begin{array}{l}\text { Risk } \\
\text { reduction }\end{array}$ & $\begin{array}{l}\text { Penerapan aturan sesuai dengan } \\
\text { metode pelaksanaan pekerjaan } \\
\text { berdasarkan SMK3. }\end{array}$ \\
\hline 10 & $\begin{array}{l}\text { Perkerasan } \\
\text { jalan }\end{array}$ & $\begin{array}{l}\text { Gangguan } \\
\text { pernafasan } \\
\text { akibat debu }\end{array}$ & 7,25 & Medium & $\begin{array}{l}\text { Risk } \\
\text { reduction }\end{array}$ & Penggunaan standar APD. \\
\hline 11 & $\begin{array}{l}\text { Galian tanah } \\
\text { dengan } \\
\text { excavator }\end{array}$ & $\begin{array}{l}\text { Tanah longsor/ } \\
\text { runtuhnya } \\
\text { dinding } \\
\text { samping }\end{array}$ & 7,13 & Medium & $\begin{array}{l}\text { Risk } \\
\text { reduction }\end{array}$ & $\begin{array}{l}\text { Memasang pagar pengaman tidak } \\
\text { hanya di daerah-daerah berisiko } \\
\text { tinggi namun pagar pengaman } \\
\text { dipasang secara menyeluruh } \\
\text { mengelilingi proyek untuk } \\
\text { sterilisasi areal proyek dari hal-hal } \\
\text { luar yang tidak ada hubungan } \\
\text { dengan jalannya proyek dan } \\
\text { memasang rambu-rambu } \\
\text { peringatan dan tanda bahaya } \\
\text { sesuai dengan standar SMK3. }\end{array}$ \\
\hline 12 & $\begin{array}{l}\text { Galian tanah } \\
\text { dengan } \\
\text { excavator }\end{array}$ & $\begin{array}{l}\text { Pekerja/ } \\
\text { Kendaraan } \\
\text { terjatuh ke } \\
\text { lubang galian }\end{array}$ & 6,82 & Medium & $\begin{array}{l}\text { Risk } \\
\text { reduction }\end{array}$ & $\begin{array}{l}\text { Penggunaan standar APD dan } \\
\text { penerapan aturan sesuai dengan } \\
\text { metode pelaksanaan pekerjaan } \\
\text { berdasarkan SMK3. }\end{array}$ \\
\hline 13 & Pengecoran & $\begin{array}{l}\text { Pekerja terjatuh } \\
\text { saat mendirikan } \\
\text { cetakan beton }\end{array}$ & 6,80 & Medium & $\begin{array}{l}\text { Risk } \\
\text { reduction }\end{array}$ & $\begin{array}{l}\text { Menerapkan aturan sesuai dengan } \\
\text { metode pelaksanaan pekerjaan } \\
\text { berdasarkan SMK3 khususnya } \\
\text { mengenai standar APD. } \\
\text { Mengasuransikan semua pekerja } \\
\text { dan pelaksana yang terlibat dalam } \\
\text { proyek melalui Jamsostek. }\end{array}$ \\
\hline 14 & $\begin{array}{l}\text { Perkerasan } \\
\text { jalan }\end{array}$ & $\begin{array}{l}\text { Pekerja terkena } \\
\text { semprotan } \\
\text { perekat (aspal } \\
\text { cair) }\end{array}$ & 6,5 & Medium & $\begin{array}{l}\text { Risk } \\
\text { reduction }\end{array}$ & $\begin{array}{l}\text { Penggunaan standar APD dan } \\
\text { penerapan aturan sesuai dengan } \\
\text { metode pelaksanaan pekerjaan } \\
\text { berdasarkan smk3. }\end{array}$ \\
\hline 15 & $\begin{array}{l}\text { Pembesian, } \\
\text { bekisting, dan } \\
\text { parapet }\end{array}$ & $\begin{array}{l}\text { Pekerja terluka } \\
\text { ketika bekerja }\end{array}$ & 6,48 & Medium & $\begin{array}{l}\text { Risk } \\
\text { reduction }\end{array}$ & $\begin{array}{l}\text { Penggunaan standar APD dan } \\
\text { penerapan aturan sesuai dengan } \\
\text { metode pelaksanaan pekerjaan } \\
\text { berdasarkan SMK3. }\end{array}$ \\
\hline 16 & $\begin{array}{l}\text { Galian tanah } \\
\text { dengan } \\
\text { excavator }\end{array}$ & $\begin{array}{l}\text { Peralatan } \\
\text { excavation } \\
\text { menabrak } \\
\text { fasilitas/pekerja } \\
\text { yang ada di } \\
\text { sekitarnya }\end{array}$ & 6,09 & Medium & $\begin{array}{l}\text { Risk } \\
\text { reduction }\end{array}$ & $\begin{array}{l}\text { Menerapkan aturan yang jelas } \\
\text { sesuai dengan metode pelaksanaan } \\
\text { pekerjaan berdasarkan SMK3 } \\
\text { khususnya mengenai standar APD } \\
\text { Mengasuransikan semua pekerja } \\
\text { dan pelaksana yang terlibat dalam } \\
\text { proyek melalui Jamsostek. }\end{array}$ \\
\hline 17 & $\begin{array}{l}\text { Instalasi } \\
\text { kabel }\end{array}$ & $\begin{array}{l}\text { Terluka ketika } \\
\text { bekerja oleh } \\
\text { alat tang press } \\
\text { hydrolic }\end{array}$ & 6,09 & Medium & $\begin{array}{l}\text { Risk } \\
\text { reduction }\end{array}$ & $\begin{array}{l}\text { Penggunaan standar APD dan } \\
\text { penerapan aturan sesuai dengan } \\
\text { metode pelaksanaan pekerjaan } \\
\text { berdasarkan SMK3. }\end{array}$ \\
\hline 18 & $\begin{array}{l}\text { Pekerjaan } \\
\text { marka jalan }\end{array}$ & $\begin{array}{l}\text { Pekerja terkena } \\
\text { gangguan } \\
\text { pernapasan } \\
\text { akibat } \\
\text { compressor }\end{array}$ & 5,50 & Medium & $\begin{array}{l}\text { Risk } \\
\text { reduction }\end{array}$ & $\begin{array}{l}\text { Penggunaan standar APD dan } \\
\text { penerapan aturan sesuai dengan } \\
\text { metode pelaksanaan pekerjaan } \\
\text { berdasarkan SMK3. }\end{array}$ \\
\hline
\end{tabular}




\section{Kesimpulan}

Sistem manajemen risiko sistem K3L pada pelaksanaan pembangunan flyover Pegangsaan 2 Kelapa Gading diharapkan dapat diterapkan pada pelaksanaan pekerjaan konstruksi tersebut, sehingga dapat menekan terjadinya kecelakaan kerja yang terjadi pada saat pelaksanaan pekerjaan konstruksi. Hal tersebut juga didukung dengan teridentifikasinya risiko kecelakaan kerja mulai dari yang paling tinggi sampai terendah dan penanganan risiko apabila terjadi kecelakaan saat pelaksanaan pekerjaan konstruksi berlangsung.

Risiko tersebut telah diurutkan sesuai dengan peringkat, diketahui indeks resiko tertinggi yaitu pada variabel Pekerja jatuh dari ketinggian pada pekerjaan pembesian, bekisting, dan parapet dengan total indeks resiko sebesar 13,8. Indeks resiko yang terendah terdapat pada variabel Pekerja terkena gangguan pernapasan akibat compressor pada pekerjaan marka jalan dengan total indeks risiko sebesar 5,5.

Berdasarkan analisis risiko yang telah dilakukan dapat disimpulkan beberapa cara mitigasi risiko berupa menerapkan aturan yang jelas sesuai dengan metode pelaksanaan pekerjaan berdasarkan SMK3, khususnya mengenai standar APD dan mengasuransikan semua pekerja dan pelaksana yang terlibat dalam proyek melalui Jamsostek.

\section{Saran}

Beberapa saran yang dapat diberikan berdasarkan hasil penelitian yang dilakukan penulis bagi para pelaksana kontraktor di lapangan yag pertama adalah pekerja Kontraktor secara keseluruhan sebaiknya memahami dan mengikuti aturan K3 yang ada, serta menjadi garda terdepan dalam memberikan contoh keteladanan kepada lingkungan sekitarnya agar mewujudkan zero accident, kemudian dalam hal penanganan risiko, dapat dilakukan berbagai hal untuk mengurangi dampak risiko, seperti menekan probability dengan cara melakukan safety induction, melakukan patroli K3 pada tiap pekerja secara rutin, memasang rambu - rambu peringatan agar pekerja selalu bekerja dengan hati-hati dan menekan severity dengan cara selalu gunakan alat pelindung diri (APD) dalam bekerja.

Saran yang dapat diberikan untuk penelitian selanjutnya adalah perlu dilakukan penelitian mengenai sistem reward dan punishment yang efektif untuk sistem manajemen risiko $\mathrm{K} 3$ dan analisis pengendalian pada mode kecelakaan untuk mencapai sasaran yaitu mencegah dan memperbaiki. Analisis yang dilakukan pada penelitian ini adalah pada pekerjaan keseluruhan pada proyek konstruksi fly over, untuk selanjutnya perlu diadakan penelitian lebih lanjut mengenai risiko kecelakaan yang spesifik pada jenis pekerjaan tertentu saja, misalnya pekerjaan marka jalan.

\section{Ucapan Terima Kasih}

Alhamdulillahirobbil alamin. Ucapan terima kasih disampaikan kepada seluruh Civitas Akademika Universitas Mercu Buana khususnya Jurusan Teknik Sipil, Ir. Mawardi Amin, M.T, PT.Waskita Karya, Teman-teman Teknik Sipil Angkatan XX UMB yang telah membantu dalam proses pengerjaan penelitian ini.

Terima kasih pula kepada keluarga yang memberikan doa dan dukungan tanpa henti. Istri tercinta Asri Arifianti, S.E. dan kedua putra Haidar Falih Sukantapradja dan Hafuza Zaid Sukantapradja.

\section{Daftar Pustaka}

Anonim. (2007). OHSAS 180001. Occupational Health and Safety System Requirements 18001:2007.

Bpjs Ketenagakerjaan. (2016, Juni 24). Konstruksi Sumbang 32 Persen dari Seluruh Kecelakaan Kerja di Indonesia. Retrieved from http://www.bpjsketenagakerjaan.go.id/berita/5797/ Konstruksi-Sumbang-32-Persen-dari-Seluruh-

Kecelakaan-di-Indonesia.html

BPS. (2016, Juni 22). Retrieved from Penduduk 15 Tahun ke Atas yang Bekerja Menurut Lapangan Pekerjaan Utama 1986-2015: https://www.bps.go.id/linkTabelStatis/view/id/970

Flanagan, R., \& Norman, G. (1993). Risk Management And Construction. Blackwell Science.

Kerzner, H. (2003). Project Management : A System Approach to Planning Schedulling, and Controlling, 8th Edition. John Wiley and Son.

Octavia, R. D. (2012). Identifikasi dan Analisa Risiko Konstruksi Dengan Metode Failure Mode And Effect Analysis (FMEA) Dan Fault Tree Analysis (FTA) pada Proyek Pembangunan Jalan Lingkar Nagreg $V$ Bandung. Surabaya: Institut Teknologi Sepuluh November.

Pritanti, H., Purwoto, \& Solechan. (2012). Pertanggungjawaban Pidana Terhadap Kontraktor 
Dalam Hal Terjadi Kecelakaan Kerja Menurut Undang-undang Nomor 3 Tahun 1992 Tentang Jaminan Sosial Tenaga Kerja. Law Journal (Universitas Diponegoro).

Siagian, F., \& Sekarsari, J. (2001). Penerapan Model Manajemen Risiko pada Proyek Konstruksi Joint Venture di Indonesia Suatu Studi Kasus. Jakarta: Universitas Trisakti.

Soputan, G. E., Sompie, B. F., \& Mandagi, R. J. (Desember 2014). Manajemen Risiko Kesehatan Dan Keselamatan Kerja (K3) (Study Kasus Pada
Pembangunan Gedung SMA Eben Haezar). Jurnal Ilmiah Media Engineering Vol.4 No.4 , 229-238.

Vaughan, E. J. (1978). Fundamentals of Risk and Insurance. Edisi Kedua.

Wicaksono, I. K., \& Singgih, M. L. (2011). Manajemen Risiko K3 (Keselamatan Dan Kesehatan Kerja) Pada Proyek Pembangunan Apartemen Puncak Permai Surabaya. Prosiding Seminar Nasional Manajemen Teknologi XIII (pp. A-54-1). 